Correspondence

Chiu-Chung Young

ccyoung@mail.nchu.edu.tw

\section{Pseudoxanthobacter soli gen. nov., sp. nov., a nitrogen-fixing alphaproteobacterium isolated from soil}

\author{
A. B. Arun, ${ }^{1}$ Peter Schumann, ${ }^{2}$ Horng-I Chu, ${ }^{1}$ Chen-Chung Tan, ${ }^{1}$ \\ Wen-Ming Chen, ${ }^{3}$ Wei-An Lai, ${ }^{1}$ Peter Kämpfer, ${ }^{4}$ Fo-Ting Shen, ${ }^{1}$ \\ P. D. Rekha, ${ }^{1}$ Mei-Hua Hung, ${ }^{1}$ Jui-Hsing $\mathrm{Chou}^{1}$ and Chiu-Chung Young ${ }^{1}$ \\ ${ }^{1}$ College of Agriculture and Natural Resources, Department of Soil and Environmental Sciences, \\ National Chung Hsing University, Taichung 402, Taiwan, ROC \\ ${ }^{2}$ DSMZ - Deutsche Sammlung von Mikroorganismen und Zellkulturen GmbH, Inhoffenstraße 7B, \\ D-38124 Braunschweig, Germany \\ ${ }^{3}$ Laboratory of Microbiology, Department of Seafood Science, National Kaohsiung Marine \\ University, No. 142, Hai-Chuan Road, Nan-Tzu, Kaohsiung City 811, Taiwan, ROC \\ ${ }^{4}$ Institut für Angewandte Mikrobiologie, Universität Giessen, Giessen, Germany
}

\begin{abstract}
A Gram-type negative or variable, aerobic, rod-shaped, nitrogen-fixing bacterium, designated strain $C C 4^{\top}$, was isolated on nutrient agar from a soil sample collected at a regional agricultural research field station located in Kaohsiung County, Taiwan. 16S rRNA gene sequence analysis demonstrated that this isolate is unique, showing $<92.5 \%$ similarity with respect to species of the genera Xanthobacter (maximum of $92.2 \%$ similarity), Prosthecomicrobium (92.0\%), Devosia $(91.9 \%)$, Kaistia (91.9\%) and Methylocystis (91.9\%). The organism utilized acetic acid, formic acid, $\beta$-hydroxybutyric acid, DL-lactic acid, succinic acid, bromosuccinic acid, L-alaninamide, Lalanine, L-alanyl glycine, L-glutamic acid and L-proline as substrates, but not methanol or methylamine. Chemotaxonomic data revealed that strain $C C 4^{\top}$ contains ubiquinone $\mathrm{Q}-10$ as the major respiratory quinone. The characteristic diamino acid of the peptidoglycan was mesodiaminopimelic acid. The major polar lipids were diphosphatidylglycerol, phosphatidylglycerol, phosphatidylethanolamine, phosphatidylcholine, phosphatidylmonomethylethanolamine, phosphatidyldimethylethanolamine, an unknown lipid and an unknown aminolipid. The fatty acid profile differed from those of members of the genera Xanthobacter, Prosthecomicrobium, Devosia and Kaistia. The predominant fatty acids were $\mathrm{C}_{18: 1} \omega 7 c, \mathrm{C}_{19: 0}$ cyclo and $\mathrm{C}_{16: 0}$. On the basis of $16 \mathrm{~S}$ rRNA gene sequence analysis in combination with chemotaxonomic and physiological data, strain $\mathrm{CC} 4^{\top}$ represents a novel genus and species, for which we propose the name Pseudoxanthobacter soli gen. nov., sp. nov. The type strain of Pseudoxanthobacter soli is CC4 ${ }^{\top}$ $\left(=\right.$ DSM $19599^{\top}=$ CIP $\left.109513^{\top}\right)$.
\end{abstract}

During the characterization of micro-organisms from soil samples from the regional agricultural research station located in Kaohsiung County, Taiwan, strain $\mathrm{CC}^{\mathrm{T}}$ was isolated and maintained on nutrient agar (NA; Oxoid) after incubation at $32{ }^{\circ} \mathrm{C}$ for 3 days. Subcultivation was done on $\mathrm{NA}$ at $30^{\circ} \mathrm{C}$ for $24 \mathrm{~h}$ to 3 days. On this medium, strain $\mathrm{CC} 4{ }^{\mathrm{T}}$ was able to grow at $15-36{ }^{\circ} \mathrm{C}$ but not at 40 or $10{ }^{\circ} \mathrm{C}$. The organism was able to grow on NA, tryptone soy agar, yeast extract-mannitol agar and R2A agar (Oxoid). Gram

The GenBank/EMBL/DDBJ accession number for the 16S rRNA gene sequence of strain $C C 4^{\top}$ is EF465533.

A scanning electron micrograph of strain $\mathrm{CC}^{\top}$ is available as supplementary material with the online version of this paper. stain set S (Difco) and the Ryu non-staining $\mathrm{KOH}$ method (Powers, 1995) were used to ascertain the Gram reaction. Poly- $\beta$-hydroxybutyrate granule accumulation was observed under light microscopy after staining of the cells with Sudan black.

Samples for scanning electron microscopy were prepared according to the method of Hahn et al. (1998) except that $4 \%$ glutaraldehyde was used to fix the cells. A TOPCON ABT-150S field emission scanning electron microscope was used to examine cells of strain $\mathrm{CC}^{\mathrm{T}}$ (see Supplementary Fig. S1, available in IJSEM Online). The following phenotypic features were investigated: biochemical characteristics, carbon-source utilization (GN2; Biolog), API 
ZYM enzyme profile (bioMérieux) and API 20E profile (bioMérieux). Additionally, antibiotic susceptibilities were tested using ATB STAPH 5 strips (bioMérieux) according to the manufacturer's recommendations. Fluorescence was tested after cells were plated on King's medium B for $48 \mathrm{~h}$.

The diaminopimelic acid isomer in whole-cell hydrolysates $\left(4 \mathrm{M} \mathrm{HCl}, 100{ }^{\circ} \mathrm{C}, 16 \mathrm{~h}\right)$ was determined using onedimensional TLC (Rhuland et al., 1955) on cellulose plates. Polar lipids extracted according to the method of Minnikin et al. (1979) were identified using two-dimensional TLC and spraying with specific reagents (Collins \& Jones, 1980). Ubiquinones were analysed as described by Tindall (1990a, b). Fatty acid methyl esters were obtained from cells cultivated on tryptic soy agar for $48 \mathrm{~h}$ at $28{ }^{\circ} \mathrm{C}$ by saponification, methylation and extraction as described previously (Kämpfer \& Kroppenstedt, 1996) and were separated in a gas chromatograph (model 5898A; Hewlett Packard). Peaks were automatically integrated and fatty acid names and percentages were determined using the Microbial Identification standard software package (MIDI, Inc.) (Sasser, 1990).

DNA for the determination of the $\mathrm{G}+\mathrm{C}$ content was isolated by using the UltraClean microbial DNA-isolation kit (MOBIO) according to the manufacturer's instructions. The DNA G $+\mathrm{C}$ content was calculated as described previously (Peña et al., 2005). Cell morphology was observed under a Zeiss light microscope at a magnification $\times 1000$, using cells that had been grown for 3 days at $30{ }^{\circ} \mathrm{C}$ on NA: the results are given in the species description.

The 16S rRNA gene sequence was analysed as described previously (Young et al., 2005). Analysis of the sequence data was performed by using the software package MEGA version 2.1 (Kumar et al., 2001), after multiple alignments of the data had been obtained using CLUSTAL_x (Thompson et al., 1997). A distance matrix method (with distance options according to Kimura's two-parameter model), including clustering by neighbour-joining (Fig. 1), and a discrete character-based maximum-parsimony method were used. In each case, bootstrap percentages were calculated on the basis of 1000 replications. The 16S rRNA gene sequence of strain $\mathrm{CC} 4^{\mathrm{T}}$ was a continuous stretch of $1488 \mathrm{bp}$. Sequence-similarity calculations indicated that strain $\mathrm{CC}^{\mathrm{T}}$ showed the greatest degree of similarity with respect to Xanthobacter agilis DSM $3770^{\mathrm{T}}$ $(92.2 \%)$, Prosthecomicrobium pneumaticum MBIC $3489^{\mathrm{T}}$ $(92.0 \%)$, Devosia neptuniae $\mathrm{J}^{\mathrm{T}}(91.9 \%)$, Kaistia adipata KCTC $12095^{\mathrm{T}}(91.9 \%)$ and Methylocystis echinoides IMET $10491^{\mathrm{T}}(91.9 \%)$. Lower sequence similarities $(<91.5 \%)$ were found with respect to all of the other genera shown in Fig. 1. The $16 \mathrm{~S}$ rRNA gene sequence of strain $\mathrm{CC} 4^{\mathrm{T}}$ is therefore distinctly different from those of members of related genera and from all other known bacteria in the Alphaproteobacteria.

Strain $\mathrm{CC} 4^{\mathrm{T}}$ contains meso-diaminopimelic acid as the characteristic diamino acid of the peptidoglycan. The major fatty acids and ubiquinones of strain $C \mathrm{C} 4^{\mathrm{T}}$ are listed in Table 1. The polar lipid chromatogram for strain $\mathrm{CC} 4{ }^{\mathrm{T}}$ is shown in Fig. 2 and the polar lipid components are listed in the species description. Results of the physiological characterization are given in the species description and in Table 1.

The strain was non-fluorescent. It was unable to produce acid from various carbohydrates. Carbon substrate utilization tests with organic acids as substrates showed few positive

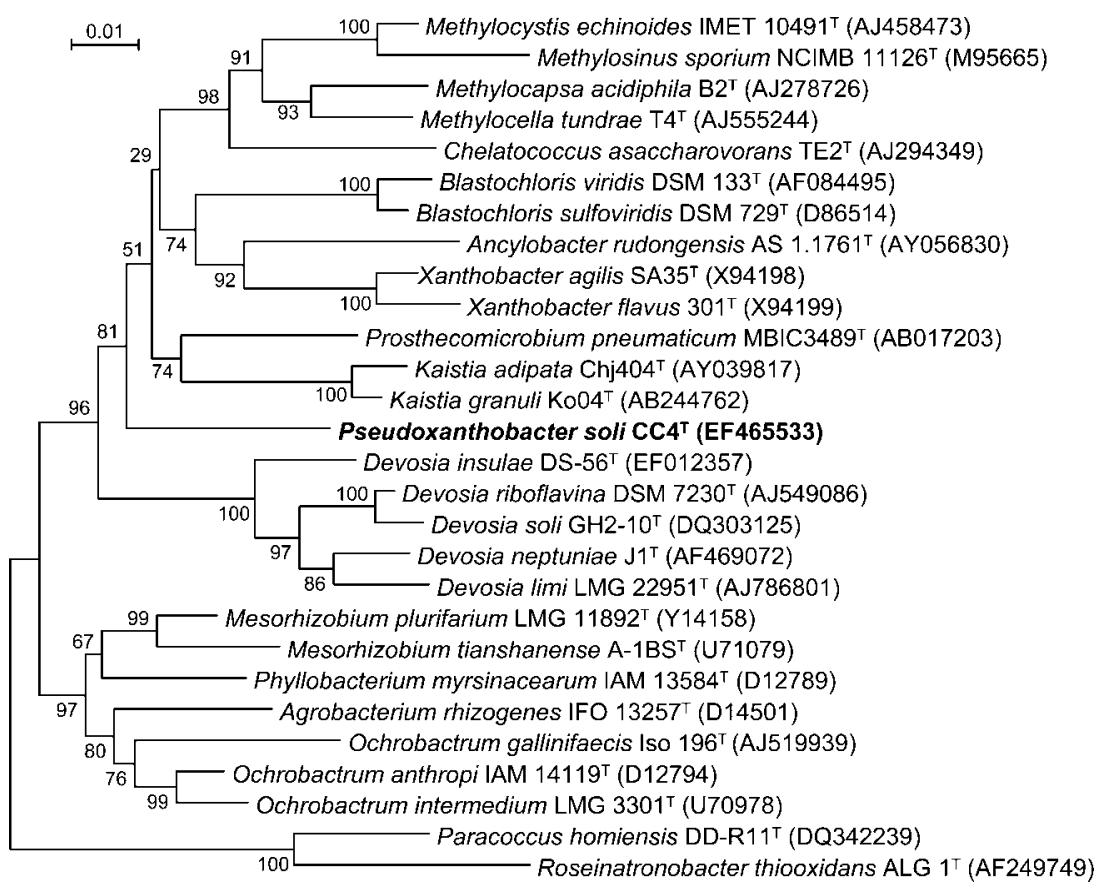

Fig. 1. Phylogenetic tree, based on $16 \mathrm{~S}$ rRNA gene sequences available from the EMBL database (accession numbers in parentheses), constructed after multiple alignment of the data by CLUSTAL_X (Thompson et al., 1997). Distances (distance options according to the Kimura-2 model) and clustering with the neighbour-joining method were obtained using MEGA, version 2.1 (Kumar et al., 2001). Bootstrap percentages (based on 1000 replications) are shown at branching points. Bar, 0.01 substitutions per nucleotide position. 
Table 1. Differential characteristics of strain $\mathrm{CC} 4{ }^{\top}$ and related genera

Taxa: 1, strain CC4 ${ }^{\mathrm{T}}$; 2, Xanthobacter (data from Wiegel, 2005; Wiegel \& Schlegel, 1984); 3, Devosia (data from Yoon et al., 2007); 4, K. adipata KCTC $12095^{\mathrm{T}}$ (data from Im et al., 2004). All the strains are catalase- and oxidase-positive and do not show pleomorphism, prosthecae, gas vacuoles or a biotin requirement. NR, Not reported; - , not detectable; $-/+$, variable; w, weak.

\begin{tabular}{|c|c|c|c|c|}
\hline Characteristic & 1 & 2 & 3 & 4 \\
\hline Motility & + & + & $-/+$ & + \\
\hline Colour of colonies & White & Pale yellow & White & White \\
\hline \multicolumn{5}{|l|}{ Growth on: } \\
\hline $\mathrm{H}_{2}+\mathrm{CO}_{2}$ at $37{ }^{\circ} \mathrm{C}$ & - & - & NR & NR \\
\hline Methanol & - & + & NR & NR \\
\hline Sorbitol & + & + & $\mathrm{NR}$ & + \\
\hline Maltose & - & NR & $-1+$ & + \\
\hline Predominant quinone(s) & Q-10, Q-9 and Q-8 & Q-10, Q-9 and Q-8 & Q-10 or Q-11 & Q-10 \\
\hline \multicolumn{5}{|c|}{ Major fatty acids ( $\%$ of total content) } \\
\hline $\mathrm{C}_{16: 0}$ & 25.4 & $1.1-10.3$ & $8.5-25.6$ & $11.0-22.2$ \\
\hline $\mathrm{C}_{18: 0}$ & 2.3 & $1.2-3.2$ & $3.2-9.3$ & $14.8-16.0$ \\
\hline
\end{tabular}

${ }^{\star}$ Summed feature 7 includes one or more of 11-methyl $\mathrm{C}_{18: 1} \omega 7 c, \mathrm{C}_{18: 1} \omega 9 t, \mathrm{C}_{18: 1} \omega 6 t, \mathrm{C}_{18: 1} \omega 7 c$ and $\mathrm{C}_{18: 1} \omega 12 t$.

results. In the API $20 \mathrm{E}$ test, $\mathrm{CC}^{\mathrm{T}}$ was positive for urease, in the Voges-Proskauer (acetoin) reaction and for oxidation of arabinose, mannose and glucose. In the API 20NE test (bioMérieux), $\mathrm{CC} 4^{\mathrm{T}}$ was positive for urease and assimilation

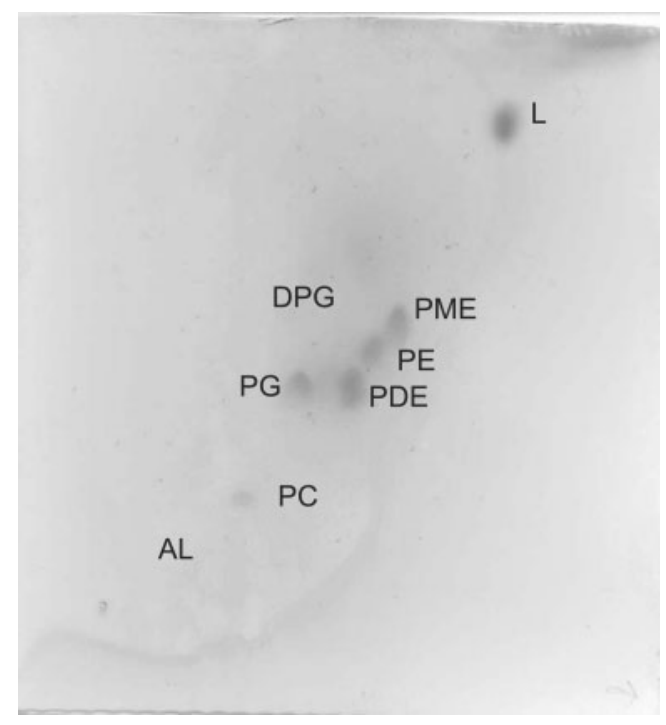

Fig. 2. Two-dimensional TLC of polar lipids of strain $C C 4^{\top}$. DPG, Diphosphatidylglycerol; PG, phosphatidylglycerol; PE, phosphatidylethanolamine; PC, phosphatidylcholine; PME, phosphatidylmonomethylethanolamine; PDE, phosphatidyldimethylethanolamine; $A L$, unknown aminolipid; $L$, unknown lipid. of glucose, arabinose, mannose, mannitol and malate. In the API ZYM enzyme profile, $\mathrm{CC}^{\mathrm{T}}$ was positive for alkaline and acid phosphatase, butyrate esterase (C4), caprylate esterase (C8), myristate lipase (C14), leucine arylamidase, trypsin and naphthol-AS-BI-phosphohydrolase.

From the results of the $16 \mathrm{~S}$ rRNA gene sequencing, it is evident that strain $\mathrm{CC}^{\mathrm{T}}$ differs from members of the genera Devosia, Xanthobacter and Kaistia and from all other genera in the phylogenetic neighbourhood. Phenotypic differentiation from all other genera in the family is possible by means of a combination of the growth characteristics, fatty acid profiles and physiological properties.

On basis of these results, we propose that strain $\mathrm{CC} 4^{\mathrm{T}}$ represents a novel genus and species, for which the name Pseudoxanthobacter soli gen. nov., sp. nov. is proposed.

\section{Description of Pseudoxanthobacter gen. nov.}

Pseudoxanthobacter (Pseu.do.xan.tho.bac'ter. Gr. adj. pseudes false; N.L. masc. n. Xanthobacter a bacterial genus name; N.L. masc. n. Pseudoxanthobacter the false Xanthobacter).

Cells are Gram-type negative or variable, aerobic, motile, short rod-shaped and non-spore-forming. Cells accumulate poly- $\beta$-hydroxybutyrate acid as polar inclusion bodies. Q-10 is the predominant ubiquinone and mesodiaminopimelic acid is the characteristic diamino acid of the peptidoglycan. Diphosphatidylglycerol, phosphatidylglycerol, phosphatidylethanolamine, phosphatidylcholine, phosphatidylmonomethylethanolamine, phosphatidyldi- 
methylethanolamine, an unknown lipid and an unknown aminolipid occur as polar lipids. The predominant fatty acids are $\mathrm{C}_{18: 1} \omega 7 c, \mathrm{C}_{19: 0}$ cyclo and $\mathrm{C}_{16: 0}$. The DNA G+C content of strain $\mathrm{CC}^{\mathrm{T}}$ is $68 \mathrm{~mol} \%$. The type species is Pseudoxanthobacter soli.

\section{Description of Pseudoxanthobacter soli sp. nov.}

Pseudoxanthobacter soli (so'li. L. neut. gen. n. soli of soil, the source of the type strain).

Positive for oxidase, acetoin and catalase; shows aerobic metabolism. Reproduction occurs by asymmetric division (budding) of the mother cell to produce a shorter daughter cell. Growth is visible after $48 \mathrm{~h}$ incubation on NA at $30{ }^{\circ} \mathrm{C}$. Cells are $0.2 \times 2.0 \mu \mathrm{m}$. Colonies on complex standard media at $37^{\circ} \mathrm{C}$ are whitish, circular, smooth and convex with entire edges. In glucose medium, acid and gas are not produced. Grows at $10-37{ }^{\circ} \mathrm{C}$ but not at $42{ }^{\circ} \mathrm{C}$. The optimum temperature for growth is $37{ }^{\circ} \mathrm{C}$. Grows at $\mathrm{pH} 5.5-10.0$ (optimally at $\mathrm{pH} 7.0$ ). The fatty acid profile of the type strain comprises $\mathrm{C}_{18: 1} \omega 7 c(34.8 \%), \mathrm{C}_{19: 0}$ cyclo $(28.2 \%), \mathrm{C}_{16: 0}(25.4 \%), \mathrm{C}_{18: 0}(2.3 \%), \mathrm{C}_{14: 0} \quad 3-\mathrm{OH}$ $(2.3 \%), \mathrm{C}_{20: 0} \quad(1.9 \%), \mathrm{C}_{18: 0} \quad 3-\mathrm{OH}(1.2 \%), \mathrm{C}_{16: 1} \omega 7 c$ (1.1\%), $\mathrm{C}_{16: 0} 3-\mathrm{OH}(0.7 \%), 11$-methyl $\mathrm{C}_{18: 1} \omega 7 c(0.5 \%)$, $\mathrm{C}_{14: 0}(0.5 \%), \mathrm{C}_{20: 2} \omega 6,9 c(0.3 \%)$ and $\mathrm{C}_{17: 0}$ cyclo $(0.2 \%)$. Shares the quinone system and polar lipids listed in the genus description. Fixes nitrogen when grown in nitrogendeficient media. In addition, methanol, methylamine and thiosulphate are not utilized. Aesculin and gelatin are not hydrolysed. Non-fluorescent. On the basis of the method described by Kämpfer et al. (1991), the type strain utilizes D-ribose, D-xylose, 4-aminobutyrate, fumarate and Lmalate but not L-arbutin, mesaconate, 2-oxoglutarate, maltitol, putrescine, adipate, azelate, suberate, L-tryptophan, 3-hydroxybenzoate or phenylacetate. On the basis of the method described by Kämpfer et al. (1991), L-alanine $p$-nitroanilide (pNA) is hydrolysed. The following compounds are not hydrolysed: $p$-nitrophenyl (pNP) $\beta$ D-galactopyranoside, pNP $\beta$-D-glucuronide, pNP $\alpha$-Dglucopyranoside, $\mathrm{pNP} \beta$-D-glucopyranoside, $\mathrm{pNP} \beta$-Dxylopyranoside, bis-pNP phosphate, bis-pNP phenylphosphonate, bis-pNP phosphorylcholine, L-aniline pNA, $\gamma$-Lglutamate pNA and L-proline pNA. No acids are produced from glucose, lactose, sucrose, D-mannitol, dulcitol, salicin, adonitol, inositol, sorbitol, L-arabinose, raffinose, rhamnose, maltose, D-xylose, trehalose, cellobiose, methyl Dglucoside, erythritol, melibiose, D-arabitol or D-mannose. The following carbon sources are utilized (positive with the Biolog GN2 system): adonitol, L-arabinose, D-arabitol, Dfructose, L-fucose, D-galactose, $\alpha$-D-glucose, myo-inositol, D-mannitol, D-mannose, D-psicose, L-rhamnose, D-sorbitol, xylitol, succinic acid monomethyl ester, acetic acid, formic acid, $\beta$-hydroxybutyric acid, DL-lactic acid, succinic acid, bromosuccinic acid, L-alaninamide, L-alanine, L-alanyl glycine, L-asparagine, L-glutamic acid, L-proline and glycerol. Weakly positive reactions are observed for Dalanine, $\alpha$-hydroxybutyric acid, L-aspartic acid and L- ornithine. The following substrates are not utilized as carbon sources: dextrin, $\alpha$-cyclodextrin, glycogen, Tweens 40 and $80, \mathrm{~N}$-acetyl-D-galactosamine, $\mathrm{N}$-acetyl-D-glucosamine, cellobiose, i-erythritol, gentiobiose, $\alpha$-D-lactose, lactulose, maltose, melibiose, methyl $\beta$-D-glucoside, raffinose, sucrose, trehalose, turanose, pyruvic acid methyl ester, cis-aconitic acid, citric acid, D-galactonic acid lactone, D-galacturonic acid, D-gluconic acid, D-glucosaminic acid, D-glucuronic acid, $\gamma$-hydroxybutyric acid, $p$ hydroxyphenylacetic acid, itaconic acid, $\alpha$-ketobutyric acid, $\alpha$-ketoglutaric acid, $\alpha$-ketovaleric acid, malonic acid, propionic acid, quinic acid, D-saccharic acid, sebacic acid, succinamic acid, glucuronamide, glycyl L-aspartic acid, glycyl L-glutamic acid, L-histidine, hydroxy-Lproline, L-leucine, L-phenylalanine, L-pyroglutamic acid, D-serine, L-serine, L-threonine, DL-carnitine, $\gamma$-aminobutyric acid, urocanic acid, inosine, uridine, thymidine, phenylethylamine, putrescine, 2-aminoethanol, 2,3butanediol, DL- $\alpha$-glycerol phosphate, $\alpha$-D-glucose 6-phosphate and D-glucose 1-phosphate. Positive for the following enzyme activities: alkaline and acid phosphatases, butyrate esterase (C4), caprylate esterase (C8), myristate lipase (C14), leucine arylamidase, trypsin and naphthol-AS-BI-phosphohydrolase. Negative for the following enzyme activities: valine arylamidase, cystine arylamidase, $\alpha$-chymotrypsin, $\alpha$-galactosidase, $\beta$-galactosidase, $\beta$-glucuronidase, $\alpha$-glucosidase, $\beta$-glucosidase, $N$ acetyl- $\beta$-glucosaminidase, $\alpha$-mannosidase and $\alpha$-fucosidase. The type strain is sensitive to cotrimoxazole, gentamicin, tetracycline, minocycline, rifampicin, norfloxacin, levofloxacin and nitrofurantoin but is resistant to penicillin, clindamycin, erythromycin, fusidic acid, plindamycin, vancomycin, teicoplanin, quinupristin-dalfopristin, coag $(-)$ oxacillin and oxacillin. Additional physiological features are given in Table 1.

The type strain, CC4 ${ }^{\mathrm{T}}\left(=\mathrm{DSM} 19599^{\mathrm{T}}=\mathrm{CIP} 109513^{\mathrm{T}}\right)$, was isolated from a soil sample collected at a regional agricultural research field station located in Kaohsiung County, Taiwan.

\section{Acknowledgements}

This research work was kindly supported by a grant from the National Science Council, Taiwan, ROC. We thank W. S. Huang for technical assistance. We thank Brian Tindall (DSMZ) for performing the ubiquinone analysis, Marlen Jando (DSMZ) for technical assistance with the analysis of the cellular fatty acids and Jean Euzéby for his advice regarding the nomenclature.

\section{References}

Collins, M. D. \& Jones, D. (1980). Lipids in the classification and identification of coryneform bacteria containing peptidoglycans based on 2,4-diaminobutyric acid. J Appl Bacteriol 48, 459-470.

Hahn, T.-W., Willby, M. J. \& Krause, D. C. (1998). HMW1 is required for cytadhesin P1 trafficking to the attachment organelle in Mycoplasma pneumoniae. J Bacteriol 180, 1270-1276. 
Im, W. T., Yokota, A., Kim, M. K. \& Lee, S. T. (2004). Kaistia adipata gen. nov., sp. nov., a novel alpha-proteobacterium. J Gen Appl Microbiol 50, 249-254.

Kämpfer, P. \& Kroppenstedt, R. M. (1996). Numerical analysis of fatty acid patterns of coryneform bacteria and related taxa. Can J Microbiol 42, 989-1005.

Kämpfer, P., Steiof, M. \& Dott, W. (1991). Microbiological characterization of a fuel-oil contaminated site including numerical identification of heterotrophic water and soil bacteria. Microb Ecol 21, 227-251.

Kumar, S., Tamura, K., Jakobsen, I.-B. \& Nei, M. (2001). MEGA2: molecular evolutionary genetics analysis software. Bioinformatics 17, 1244-1245.

Minnikin, D. E., Collins, M. D. \& Goodfellow, M. (1979). Fatty acid and polar lipid composition in the classification of Cellulomonas, Oerskovia and related taxa. J Appl Bacteriol 47, 87-95.

Peña, A., Valens, M., Santos, F., Buczolits, S., Antón, J., Kämpfer, P., Busse, H.-J., Amann, R. \& Rosselló-Mora, R. (2005). Intraspecific comparative analysis of the species Salinibacter ruber. Extremophiles $\mathbf{9}$, 151-161.

Powers, E. M. (1995). Efficacy of the Ryu nonstaining KOH technique for rapidly determining gram reactions of food-borne and waterborne bacteria and yeasts. Appl Environ Microbiol 61, 3756-3758.

Rhuland, L. E., Work, E., Denman, R. F. \& Hoare, D. S. (1955). The behavior of the isomers of $\alpha, \varepsilon$-diaminopimelic acid on paper chromatograms. J Am Chem Soc 77, 4844-4846.
Sasser, M. (1990). Identification of bacteria by gas chromatography of cellular fatty acids. USFCC Newsl 20, 16.

Thompson, J. D., Gibson, T. J., Plewniak, F., Jeanmougin, F. \& Higgins, D. G. (1997). The CLUSTAL_X windows interface: flexible strategies for multiple sequence alignment aided by quality analysis tools. Nucleic Acids Res 25, 4876-4882.

Tindall, B. J. (1990a). A comparative study of the lipid composition of Halobacterium saccharovorum from various sources. Syst Appl Microbiol 13, 128-130.

Tindall, B. J. (1990b). Lipid composition of Halobacterium lacusprofundi. FEMS Microbiol Lett 66, 199-202.

Wiegel, J. K. W. (2005). Genus XX. Xanthobacter Wiegel, Wilke, Baumgarten, Opitz and Schlegel 1978, 573 ${ }^{\mathrm{AL}}$. In Bergey's Manual of Systematic Bacteriology, 2nd edn, vol. 2, part C, pp. 555-566. Edited by D. J. Brenner, N. R. Krieg, J. T. Staley \& G. M. Garrity. New York: Springer.

Wiegel, J. K. W. \& Schlegel, H. G. (1984). Genus Xanthobacter Wiegel, Wilke, Baumgarten, Opitz and Schlegel 1978, 573 ${ }^{\mathrm{AL}}$. In Bergey's Manual of Systematic Bacteriology, vol. 1, pp. 325-333. Edited by N. R. Krieg \& J. G. Holt. Baltimore: Williams \& Wilkins.

Yoon, J.-H., Kang, S.-J., Park, S. \& Oh, T. K. (2007). Devosia insulae sp. nov., isolated from soil of Dokdo in Korea, and emended description of the genus Devosia. Int J Syst Evol Microbiol 57, 1310-1314.

Young, C.-C., Kämpfer, P., Shen, F.-T., Lai, W.-A. \& Arun, A. B. (2005). Chryseobacterium formosense sp. nov., isolated from the rhizosphere of Lactuca sativa L. (garden lettuce). Int J Syst Evol Microbiol 55, 423-426. 